\title{
Role of strain induced crystallization and oxidative crosslinking in fracture properties of rubbers
}

\author{
Pierre Yves Le Gac ${ }^{\mathrm{a}, *}$, Morgane Broudin ${ }^{\mathrm{a}}$, Gérard Roux ${ }^{\mathrm{b}}$, Jacques Verdu ${ }^{\mathrm{c}}$, Peter Davies ${ }^{\mathrm{a}}$, \\ Bruno Fayolle
}

\begin{abstract}
a IFREMER, Centre de Bretagne, Marine Structures Laboratory, BP70, 29280 PLOUZANE, France
${ }^{b}$ Thales Underwater Systems, TUS, route des Dolines, BP 157, 06903 Sophia-Antipolis Cedex, France

${ }^{c}$ PIMM, Arts et Métiers ParisTech, 151 Bd de l'Hôpital, F-75013 PARIS
\end{abstract}

*: Corresponding author : Pierre Yves Le Gac

\begin{abstract}
:
Tensile properties and crack propagation properties, especially critical strain energy release rate in mode I, $G_{I C}$, have been used to investigate fracture properties of elastomers and their relationships with microstructure. These investigations were mainly based on a series of comparisons: first, the behaviour of polychloroprene rubber (CR), undergoing stress hardening due to strain induced crystallization (SIC) and oxidative crosslinking (OCL) was compared with that of chlorinated polyethylene (CPE), which undergoes SIC but not OCL, and with a polyurethane based on hydroxyl terminated polybutadiene (PU) which undergoes OCL but not SIC. Comparisons were also made on $\mathrm{CR}$ between fracture behaviour at ambient temperature, where $\mathrm{SIC}$ occurs and at $100^{\circ} \mathrm{C}$ where there is no SIC. Finally, oxidative crosslinking was used to vary in a continuous way the crosslink density in $\mathrm{CR}$ and $\mathrm{PU}$, in order to evaluate the role of crosslinking in fracture behaviour.
\end{abstract}

The results reveal the strong contribution of SIC to fracture strength. Crosslinking, even at low conversion, inhibits SIC which explains the sharp decrease of CR toughness in the early period of exposure to oxidation. When SIC has disappeared, it is possible to appreciate the effect of crosslinking on fracture behaviour. This effect, as evaluated from the density of deformation energy at rupture in tension or from $G_{I C}$ value, is almost negligible while the sample modulus increases regularly as a consequence of crosslinking. It appears that the toughness remains almost constant because it is under the influence of two contradictory phenomena: the negative effect of a reduction of ultimate elongation and the positive effect of a modulus increase. Such behaviour can be explained in terms of heterogeneous distribution of the lengths of elastically active chains. After long exposure, the sample behaviour becomes brittle, very high modulus values indicate that the samples approach, presumably in a heterogeneous way, the glassy state. 


\section{Graphical Abstract}

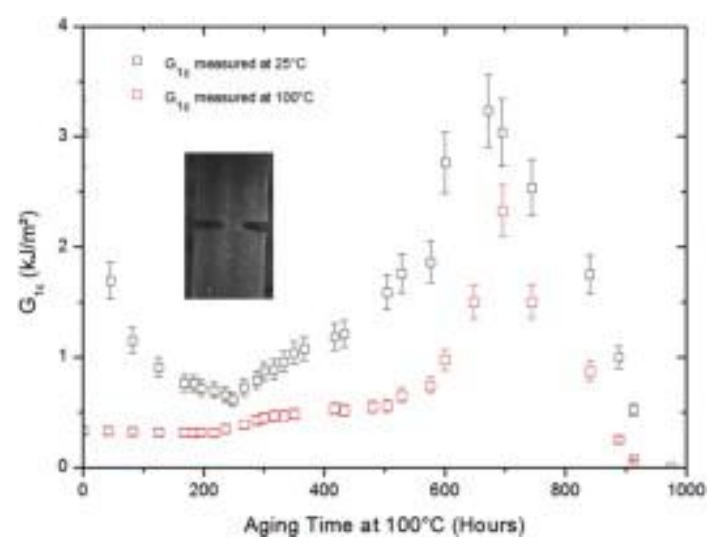

Keywords : Fracture ; Rubber ; oxidation (3) 


\section{INTRODUCTION}

This article deals with fracture properties of chlorinated elastomers, their relationships with structure, and the consequences of their oxidative ageing on these properties. There is a relatively abundant literature on the effect of crosslink density on fracture properties of elastomers. These studies have been performed essentially on network families of well controlled architecture such as crosslinked polydimethyl siloxanes [1] [2] or polyurethane elastomers [3], in which all the additives susceptible to modify the mechanical behaviour, especially fillers, were avoided. A peculiar attention has been paid to the quasi equilibrium properties which could be deduced from the network theory and the theory of entropic elasticity applied to quasi ideal networks in which the length distribution of elastically active chains (EAC) would be unimodal. In such cases, a key characteristic is the number of chains crossing an unit area in unloaded state [4]; according to Lake [5] , there is a simple relationship with the molar mass $\mathrm{M}_{\mathrm{c}}$ of EACs:

$\mathrm{G}_{\mathrm{Ic} 0}=\mathrm{KM}_{\mathrm{C}}{ }^{1 / 2}$

Where $\mathrm{G}_{\mathrm{Ic} 0}$ is the threshold tear strength that characterizes fracture free of viscoelastic or strain induced crystallization (SIC) effects. $\mathrm{K}$ is mainly related to the rupture energy of a single chain. This kind of relationship has been experimentally checked by various authors [6] [7] [8], but counter-examples have also been found. For instance Yanyo observed that in polydimethyl siloxane networks, the fracture behaviour depends also on the length distribution of EACs [9]. This was confirmed by Mark and co-workers [1] [2] who studied a series of polydimethyl siloxane networks based on long chains to which variable quantities of short chains were added. It appeared that the modulus increases regularly with the average crosslink density. In contrast, the ultimate elongation does not vary with the crosslink density except at high concentrations of short chains, showing that in a wide interval of crosslink densities, for a bimodal network, the fracture behaviour remains controlled by the extension of long chains. In such systems, indeed, the fracture energy increases regularly with crosslink density as long as ultimate elongation remains constant.

"Equilibrium" fracture properties are interesting from a theoretical point of view but they do not correspond to the real use conditions of rubbers. Under such conditions, 
6

viscoelastic effects cannot be ignored. Persson [10] proposed a simple equation to represent the contribution of viscoelasticity to toughness:

$\mathrm{G}_{\mathrm{Ic}}=\mathrm{G}_{\mathrm{Ic} 0}[1+\varphi(\mathrm{T}, \mathrm{v})]$

Where $\mathrm{G}_{\mathrm{Ic} 0}$ is the "equilibrium" $\mathrm{G}_{\mathrm{Ic}}$ value and $\varphi(T, \mathrm{v})$ is a function of temperature $T$ and crack velocity $\mathrm{v}$ expressing the contribution of dissipative, viscoelastic processes to fracture energy. This approach has been used recently in a study of fracture properties of polyurethane elastomers by Cristiano et al. [3]. The fracture behaviour depends not only on crosslink density but also on the type of crosslinks [11].

Some elastomers, e.g. natural rubber at elongations higher than c.a. $200 \%$, undergo strain induced crystallization (SIC) [12] [13] [14] [15] [16] [17], because they have a regular chain structure and, due to entropic effects linked to chain orientation, their melting point tends to become higher than the test temperature. Crystallization at the crack tip increases the crack propagation energy significantly. In other words, SIC improves the fracture strength substantially [12].

The technological interest of SIC has resulted in a large number of studies which were recently reviewed by Huneau [17] who concluded that there is an optimum crosslink density of the order of $0.13 \mathrm{~mol} / \mathrm{kg}$ to obtain the highest SIC effect. At low crosslink densities, crosslinks favour chain orientation upon tensile loading because they prevent loss of orientation by chain relaxation. At high crosslink density, crosslinks appear as defects limiting crystallinity.

For the family of unsaturated elastomers, oxidative crosslinking is often the major mode of atmospheric thermal ageing because in these polymers, macro-radical addition to double bonds is an important propagation process for radical oxidation. Indeed, intermolecular addition, responsible for crosslinking, coexists with intramolecular addition, responsible for cycle formation and eventually with other processes such as chain scission, but in several cases, among which the polychloroprene (CR) and polyurethane (PU) studied here, crosslinking predominates. It seemed to us interesting to study its consequences on fracture behaviour, which can bring valuable data, both in the domain of structure-property relationships and in the domain of rubber ageing. 
7

The fracture properties of elastomers have already been studied from this point of view [18] [19] [20] [21] [22] [23] [24], including studies on polychloroprene [19] [20], but unfortunately the measurements were made on thick samples. In these oxidation is diffusion controlled [25] in such a way that an aged sample tends to adopt a sandwich structure with an undegraded core and two degraded superficial layers. Indeed, the change in fracture properties of such samples is not easy to interpret. For this reason it seemed to us interesting to study the effect of oxidative ageing on samples either undergoing crosslinking or not, and either displaying or not SIC. For the interpretation of oxidation mechanisms and kinetics, we used classical theories [26] [27] but powerful numerical tools are available for the resolution of kinetic schemes [28]. 
8

2 - Materials and Methods

\subsection{Materials}

The three elastomers considered in this study are polychloroprene (CR), chlorinated polyethylene (CPE) and polyurethane (PU). CR is a sulphur cured material. CPE is a peroxide cured material without any fillers and the PU is made of hydroxyl terminated polybutadiene (PBHT) cured by the diisocyanate derived from methylene dianiline (MDI) in stoichiometric ratio. It should be noted that none of these materials contain any stabilization additives nor reinforcing fillers. Initial molar mass between crosslinks, $M_{c}$ has been evaluated from tensile modulus measurements using the classical rubber theory linking the molar mass between crosslinks and the rubber modulus [29]:

$$
\mathrm{Mc}=\frac{\rho \cdot R T\left(\lambda-\lambda^{-3}\right)}{\sigma}
$$

Where $\rho$ is density, $R$ is the gas constant, T is temperature in $K, \lambda$ is elongation and $\sigma$ is stress.

These data are reported in table 1. Tg was measured using Q200 DSC with a typical $10^{\circ} \mathrm{C} / \mathrm{min}$ scanning speed.

\begin{tabular}{lccccc}
\hline \multicolumn{1}{c}{ Elastomer } & Acronym & $\begin{array}{c}\text { Modulus } \\
(\mathrm{MPa})\end{array}$ & $\begin{array}{c}\text { Density } \\
\left(\mathrm{g} / \mathrm{cm}^{3}\right)\end{array}$ & $\begin{array}{c}\mathrm{M}_{\mathrm{C}} \\
(\mathrm{kg} / \mathrm{mol})\end{array}$ & \begin{tabular}{c}
$\mathrm{T}_{\mathrm{g}}\left({ }^{\circ} \mathrm{C}\right)$ \\
\hline polychloroprene
\end{tabular} \\
$\begin{array}{l}\text { chlorinated polyethylene } \\
\text { polyurethane }\end{array}$ & $\mathrm{CPE}$ & 2.91 & 1.17 & 2.99 & $-21^{\circ} \mathrm{C}$ \\
\hline
\end{tabular}

Table 1 : Initial characteristics of rubbers used in this study

\subsection{Ageing}


9

Ageing was performed on 200 micrometers thick films in Memmert ovens with forced convection at 100,120 and $140+/-2^{\circ} \mathrm{C}$. These temperatures have been chosen high enough to obtain significant changes in reasonably short times. Special care was taken on homogeneity of the degradation through sample thickness in order to avoid diffusion limited oxidation (DLO). This latter aspect has been studied previously for oxidation of CR [25] and PU-PB [30]. The films were cut from bulk samples, cooled by liquid nitrogen, with a Leica microtome.

\subsection{Molecular modification}

Chemical modifications such as double bond consumption and carbonyl formation have been followed by FTIR spectroscopy in transmission mode using thin films (about 10 microns). During exposure, FTIR analyses have been performed on a Perkin Elmer Spectrum 2 with a resolution of $4 \mathrm{~cm}^{-1}$ and double bond concentration has been assessed by using the peak at $1660 \mathrm{~cm}^{-1}$ (typical FTIR results are plot in appendix 1). In order to convert the absorbance at $1660 \mathrm{~cm}^{-1}$ into a concentration value, the Beer-Lambert law has been used with a molar absorptivity equal to $251 . \mathrm{mol}^{-1} \cdot \mathrm{cm}^{-1}$ [30].

\subsection{Changes in crosslink density}

Modulus change during oxidation was measured in situ on 100 micrometers thick films using a TA Instrument DMA (2980). Samples were tested in tensile mode at a frequency of $1 \mathrm{~Hz}$, with a displacement amplitude of $5 \mu \mathrm{m}$. Specimen dimensions were $10 \mathrm{~mm}$ length and $4 \mathrm{~mm}$ width. The average crosslink density $v=\left(\mathrm{M}_{\mathrm{c}}\right)^{-1}$ was assessed from modulus based on equation 3 .

\subsection{Tensile test}

Tensile tests were performed using standard dog bone specimens (type 2 from ISO 37) on an Instron machine with a displacement rate of $10 \mathrm{~mm} / \mathrm{min}$. Sample deformation was measured using crosshead displacement and load was measured with a $500 \mathrm{~N}$ load cell. For each condition, three samples of $0.9 \mathrm{~mm}$ thickness were tested. 
Dynamic mechanical analysis was performed on a $Q 800$ device from TA Instruments. Measurements were performed in tensile mode at $1 \mathrm{~Hz}$ with a dynamic strain of 0.2 and a static force of $1 \mathrm{~N}$ on $17 \mathrm{~mm} * 5 \mathrm{~mm} * 0.9 \mathrm{~mm}$ samples. Heating rate was $2{ }^{\circ} \mathrm{C} / \mathrm{min}$ between -80 and $100^{\circ} \mathrm{C}$.

\section{$2.7 \quad G_{I c}$ measurement}

$\mathrm{G}_{\mathrm{Ic}}$ measurements were performed on a Metravib DMA $150 \mathrm{~N}$ machine using a $2 \mathrm{~N}$ load cell (XFTC300) from Measurement Specialists, in double notched tensile mode, with a strain rate of $6.710^{-4} \mathrm{~s}^{-1}$. Samples were 200 micrometers thick with a typical length of $10 \mathrm{~mm}$ and a width of $5 \mathrm{~mm}$. They were notched on each side using a new razor blade, distance between the two notches (ligament length, L) is about $1 \mathrm{~mm}$. The validity of these tests was established in a preliminary study which examined the effect of strain rate and ligament length, more details are available in [31]. Tests were performed inside a transparent oven, in order to record experiments with a high resolution camera (Camera Basler PIA 2400-12GM). Images from the camera were used to measure the actual ligament length (L) before testing and fracture energy was measured from load/displacement curve, the following expression was used to determine $\mathrm{G}_{\mathrm{Ic}}$ :

$$
G 1 c=\frac{\int P d U}{t * L}
$$

Where $\mathrm{P}$ is the load in $\mathrm{N}, \mathrm{U}$ is displacement in $\mathrm{m}, \mathrm{t}$ is sample thickness in $\mathrm{m}$ and $\mathrm{L}$ distance between the two notches in $\mathrm{m}$.

For CR and CPE, fracture energy was measured at two different temperatures (25 and $100^{\circ} \mathrm{C}$ ) in order to evaluate the contribution of strain induced crystallisation (which does not occur at $100^{\circ} \mathrm{C}$ ) to the $\mathrm{G}_{\mathrm{IC}}$ measurement. A typical standard deviation of $10 \%$ of the fracture value was observed for each measurement, this standard deviation was determined at three different ageing stages by doing 5 times the same experiment. 


\section{Results}

Network modification induced by oxidation

Molecular changes during oxidation were followed by both FTIR and in situ modulus measurements. In FTIR spectra of CR, two bands are modified during exposure: absorption decreases for the peak at $1660 \mathrm{~cm}^{-1}$ associated to double bonds, and absorption increases for the peak at $1790 \mathrm{~cm}^{-1}$ associated with carbonyl (presumably acid chloride) groups. Oxidation leads to carbon-carbon double bond consumption, this consumption is mainly due to radical additions to double bonds. According to Celina [25], in CR, certain macro-radical additions to double bonds create new crosslinks and changes in the crosslink density. The change in crosslink density can be directly calculated from tensile modulus using the basic theory of rubber elasticity [29]. Examples of tensile curves obtained after ageing at $100^{\circ} \mathrm{C}$ are shown in Figure 1. It can be seen that the tangent modulus increases regularly during ageing, this can be attributed to predominant crosslinking. It is interesting to plot the number $x=M_{c}^{-1} / 2$ of crosslinks against the number of consumed double bonds in Figure 2. In the early period of exposure, $x$ increases almost proportionally with number of consumed double bonds and the ratio is of the order of 0.1 , independent of temperature. This point will be discussed later.

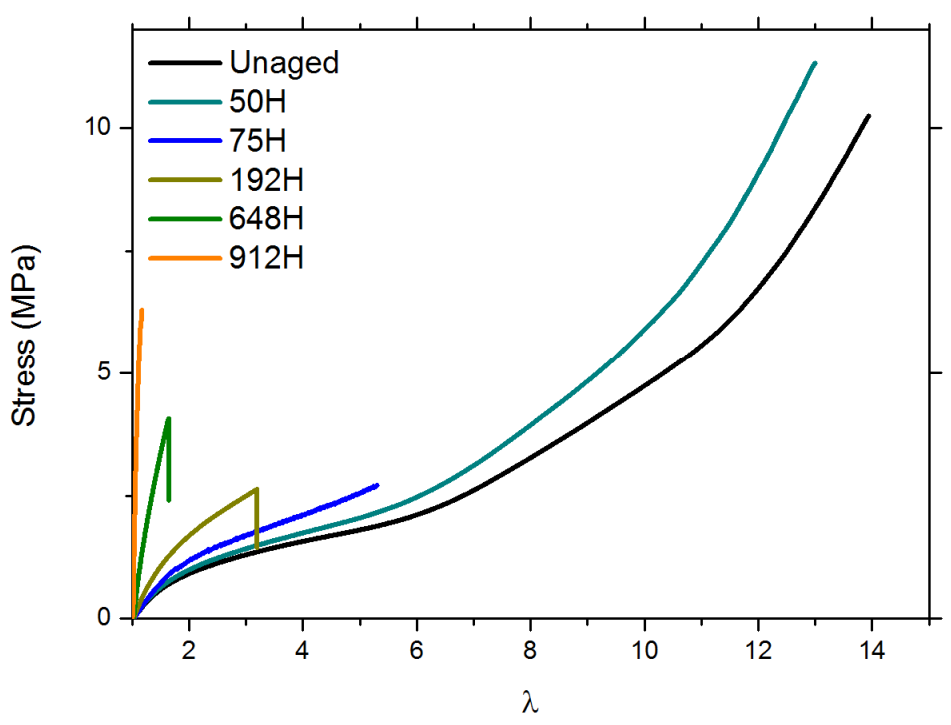

Figure 1: Change in tensile behaviour during $\mathrm{CR}$ oxidation at $100^{\circ} \mathrm{C}$ 


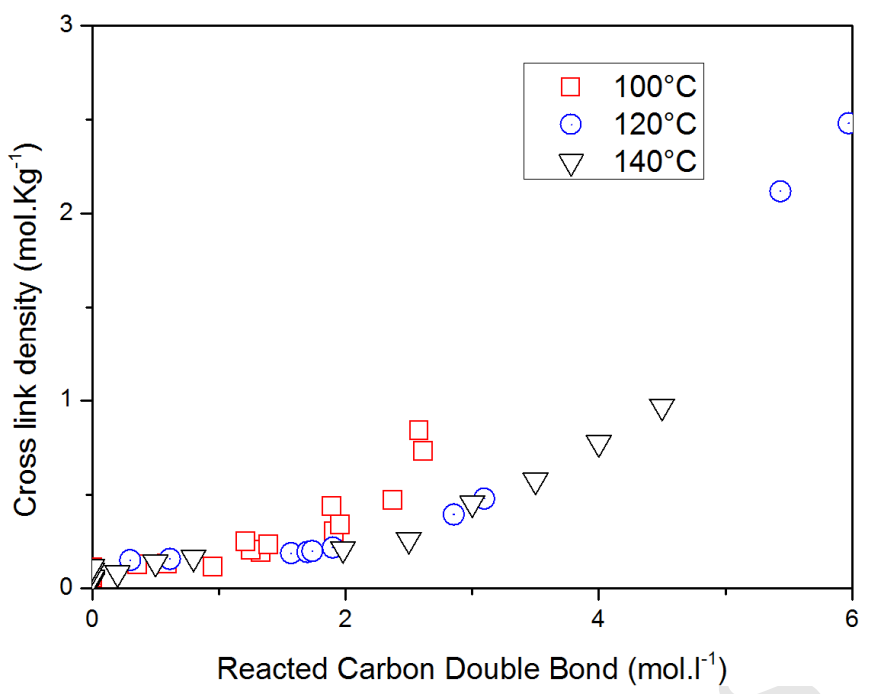

Figure 2 : Crosslink density evolution during oxidation related to reacted carbon double bonds

DMA spectra can bring interesting complementary information as illustrated by the plots of real (E') component of the complex tensile modulus against temperature for various ageing durations at $100^{\circ} \mathrm{C}$ (Figure 3). For low ageing duration a typical rubbery behaviour is observed with a $\mathrm{T}_{\mathrm{g}}$ around $-30^{\circ} \mathrm{C}$ (Figure3). $\mathrm{T}_{\mathrm{g}}$ increases slightly with ageing time, as expected for a crosslinking process, but the most striking fact is that for long durations (i.e. 288 hours and more), the rubbery plateau tends to be masked by a broadening of the glass transition. Between $-30^{\circ} \mathrm{C}$ and $60^{\circ} \mathrm{C}$, the modulus increases by a factor at least equal to 10 after 816 hours of exposure. Such broadening of the glass transition zone can be explained as follows: crosslinking leads to a progressive glass transformation (at $-30^{\circ} \mathrm{C}<\mathrm{T}<100^{\circ} \mathrm{C}$ ) of the polymer but this transformation is not homogeneous, it occurs first in randomly distributed micro-domains and then progressively invades the sample volume. The fact that these changes cannot be explained by homogeneous crosslinking is attested by the numerical modulus value at $30^{\circ} \mathrm{C}$ after 816 hours: about $100 \mathrm{MPa}$. Applying the basic theory of rubber elasticity this leads to a molar mass of elastically active chains $\mathrm{M}_{\mathrm{c}}=105 \mathrm{~g} / \mathrm{mol}$ when the molar mass of monomeric units is $88.5 \mathrm{~g} / \mathrm{mol}$. It would be difficult to imagine a network displaying this average crosslink density in which the more densely crosslinked regions would not be glassy. 
14
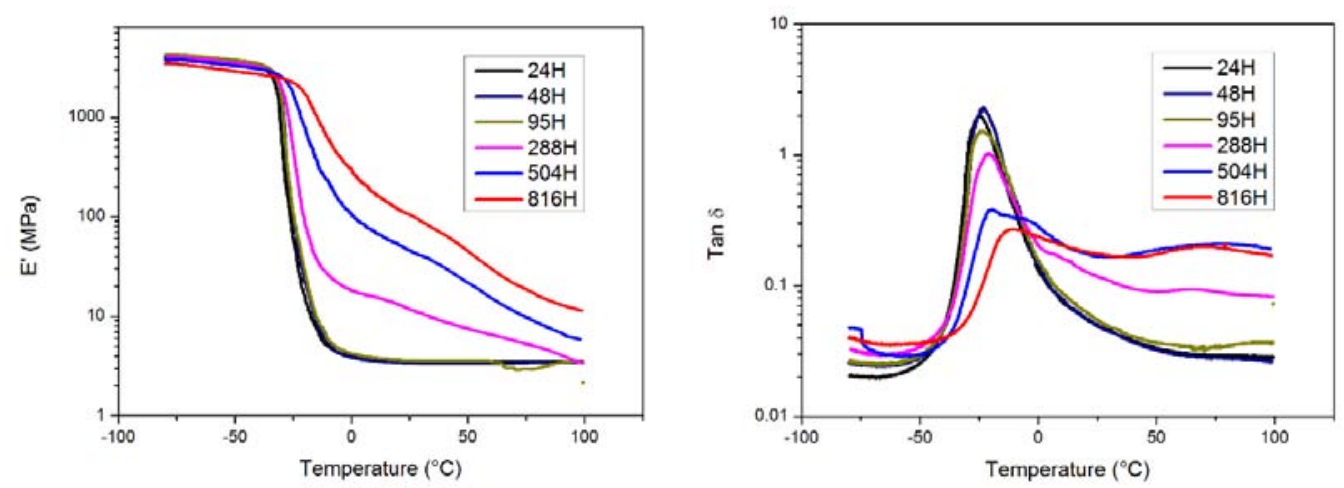

Figure 3 : Evolution of DMA results (modulus and tan $\delta$ ) for different ageing durations

Effect of temperature on the toughness of virgin samples

$\mathrm{G}_{\mathrm{IC}}$ of virgin $\mathrm{CR}$ samples has been plotted against temperature in Figure 4. $\mathrm{G}_{\mathrm{IC}}$ decreases almost hyperbolically from $2.8 \mathrm{~kJ} / \mathrm{m}^{2}$ at $25^{\circ} \mathrm{C}$ to $0.9 \mathrm{~kJ} / \mathrm{m}^{2}$ at $80^{\circ} \mathrm{C}$.

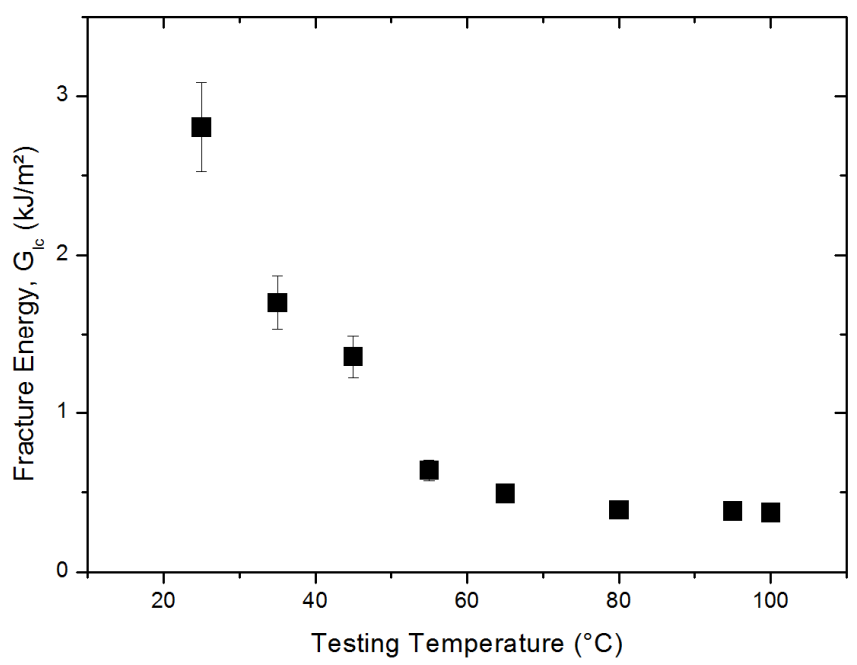

Figure 4 : Evolution of fracture energy of CR with testing temperature 
Measurements on CPE indicated about $4.6 \mathrm{~kJ} / \mathrm{mol}$ at $25^{\circ} \mathrm{C}$ and $0.6 \mathrm{~kJ} / \mathrm{mol}$ at $100^{\circ} \mathrm{C}$. For $\mathrm{PU}$, the $\mathrm{G}_{\mathrm{IC}}$ value at $25^{\circ} \mathrm{C}: \sim 0.2 \mathrm{~kJ} / \mathrm{mol}$, is of the same order as the $100^{\circ} \mathrm{C}$ values for $\mathrm{CR}$ and CPE. It was not determined at $100^{\circ} \mathrm{C}$. These results can be easily explained by the fact that CR and CPE have in common their ability to develop SIC which is not the case of PU. But SIC can exist only in the temperature domain below the melting point of crystals made of extended chains. As observed here, this melting point is higher than $25^{\circ} \mathrm{C}$ but lower than $100^{\circ} \mathrm{C}$. These comparisons reveal the key role of SIC in rubber toughness at ambient temperature.

\section{Fracture properties of CR from tensile testing}

For CR samples exposed at $100^{\circ} \mathrm{C}$, the ultimate stretching ratio $\lambda_{r}$ and the strain energy density at rupture $W_{r}$ i.e. the area under the tensile curve, have been plotted against exposure time in Figure 5. After a short ( 50 hours) "induction period", the ultimate strain and the strain energy density at rupture drop off abruptly by about one order of magnitude. This change can be attributed to the disappearance of the portion of the tensile curve (Figure 1) having a positive curvature, which was attributed to the hardening effect of SIC. After this period, the ultimate properties continue to decrease, first slowly, but with a slight tendency to accelerate at long term.
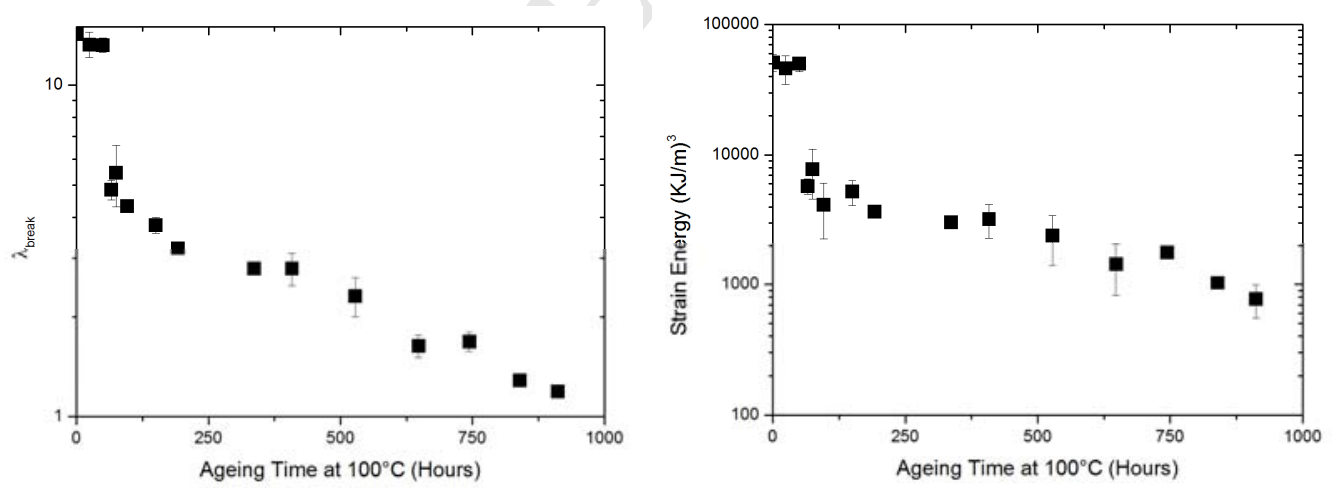

Figure 5 : Evolution of fracture properties (elongation at break and strain energy) obtained in tensile tests during $\mathrm{CR}$ oxidation at $100^{\circ} \mathrm{C}$

Fracture properties of CR from crack propagation characteristics 
Both values of $\mathrm{G}_{\mathrm{IC}}$ measured at $25^{\circ} \mathrm{C}$ and $100^{\circ} \mathrm{C}$ on $\mathrm{CR}$ samples have been plotted against exposure time at $100^{\circ} \mathrm{C}$ in Figure 6 . These figures allow at least three periods to be distinguished: period I 0 to 200 hours; period II 200 to $600-700$ hours; period III > 600-700 hours.

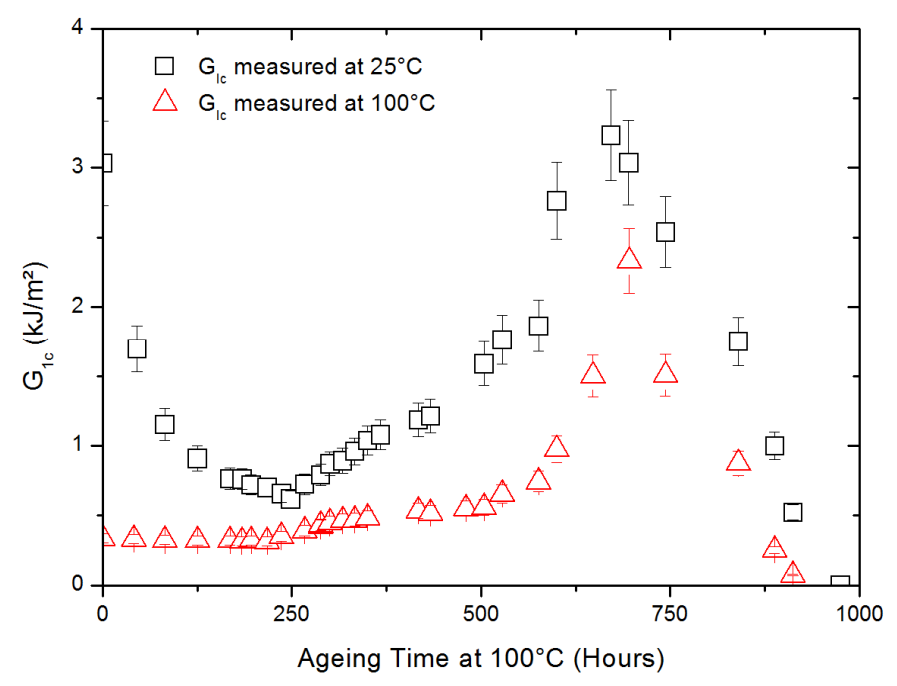

Figure 6 : $\mathrm{G}_{1 \mathrm{c}}$ evolution for $\mathrm{CR}$ during oxidation at $100^{\circ} \mathrm{C}$

The period I, during which $\mathrm{G}_{\mathrm{IC}}\left(25^{\circ} \mathrm{C}\right)$ decreases almost exponentially, closely corresponds to the period of fast decay of ultimate tensile properties with however one difference: no "induction period" is observed here. In the same period, no significant variation was observed for $\mathrm{G}_{\mathrm{IC}}\left(100^{\circ} \mathrm{C}\right)$.

During the period II, both $\mathrm{G}_{\mathrm{IC}}\left(25^{\circ} \mathrm{C}\right)$ and $\mathrm{G}_{\mathrm{IC}}\left(100^{\circ} \mathrm{C}\right)$ increase up to a maximum after 600-700 hours of exposure.

During the period III, both $\mathrm{G}_{\mathrm{IC}}\left(25^{\circ} \mathrm{C}\right)$ and $\mathrm{G}_{\mathrm{IC}}\left(100^{\circ} \mathrm{C}\right)$ decay rapidly to reach values lower than $0.1 \mathrm{~kJ} / \mathrm{mol}$ after 900 hours of exposure.

The same behaviour can be observed on samples exposed at $120^{\circ} \mathrm{C}$ or $140^{\circ} \mathrm{C}$ (Figure $7 \mathrm{a}$ ). A typical Arrhenius behaviour can be used to build a master curve of $\mathrm{G}_{\mathrm{IC}}$ evolution independent of ageing temperature (in the 100 to $140^{\circ} \mathrm{C}$ range - Figure $7 \mathrm{~b}$ ). This 
approach cannot be used to make reliable life time prediction for lower temperatures because of a possible non Arrhenian behaviour for lower temperature.
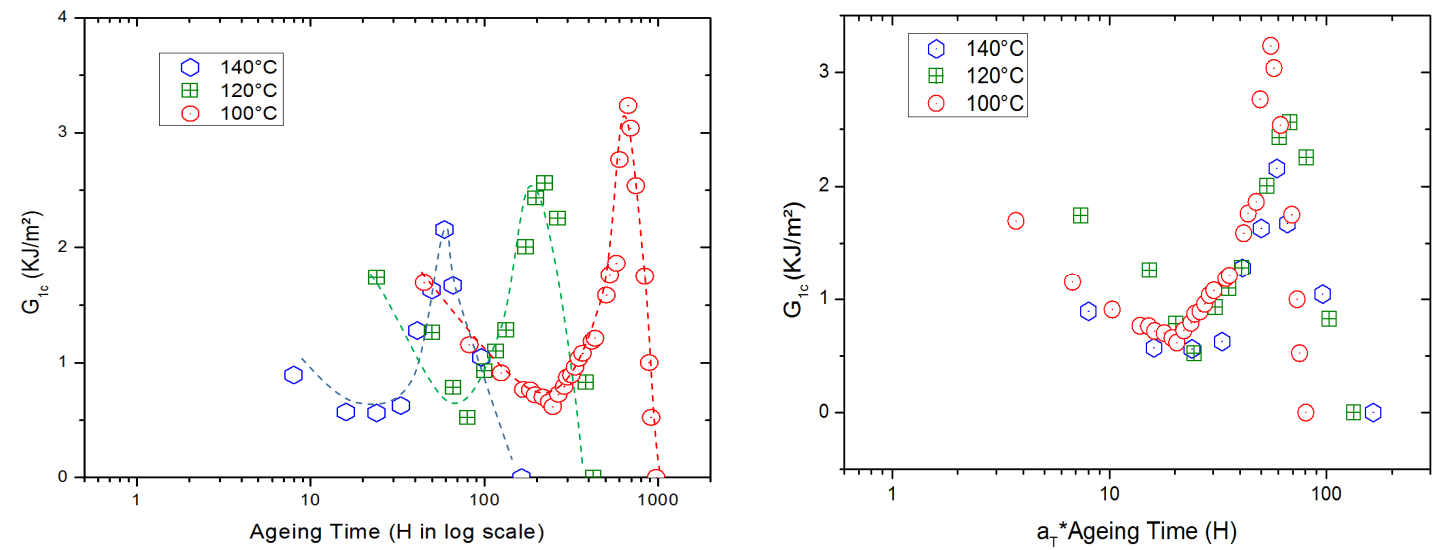

Figure 7: Effect of ageing temperature on $\mathrm{G}_{\mathrm{IC}}$ evolution measured at $25^{\circ} \mathrm{C}$ during oxidation of CR a) Raw data, b). Shifted plots 
Comparison of $C R$ with other elastomers

Some elements of comparison of CR with chlorinated polyethylene (CPE) and isocyanate cured polybutadiene (PU) are summarized in Figure 8. Figure 8a shows the modulus changes during exposure at $120^{\circ} \mathrm{C}$. It can be seen that both unsaturated polymers, $\mathrm{CR}$ and PU undergo crosslinking whereas $\mathrm{CPE}$, in which there is an initial modulus decrease, undergoes first predominant chain scission. Toughness changes are displayed in Figure $8 \mathrm{~b}$ for CR, 8c for CPE and Figure 8d for PU. They call for the following comments:

In CPE, the strong difference between $\mathrm{G}_{\mathrm{IC}}$ values at $25^{\circ} \mathrm{C}$ and $100^{\circ} \mathrm{C}$ indicates, as previously quoted, the existence of SIC. The SIC effect does not disappear: it remains almost constant during an early period of exposure of about 120 hours and then decreases but remains active, even after 300 hours at $120^{\circ} \mathrm{C}$. It can be recalled that $\mathrm{CPE}$ does not undergo crosslinking.

PU $\left(\mathrm{G}_{\mathrm{IC}}\right.$ at $\left.25^{\circ} \mathrm{C}\right)$ behaves as $\mathrm{CR}\left(\mathrm{G}_{\mathrm{IC}}\right.$ at $\left.100^{\circ} \mathrm{C}\right)$ : $\mathrm{G}_{\mathrm{IC}}$ increases rapidly during the early period of exposure, reaches a maximum after about 40 hours at $120^{\circ} \mathrm{C}$ and then decreases rapidly. It should be recalled that $\mathrm{CR}$ and PU have in common that both can undergo crosslinking. 

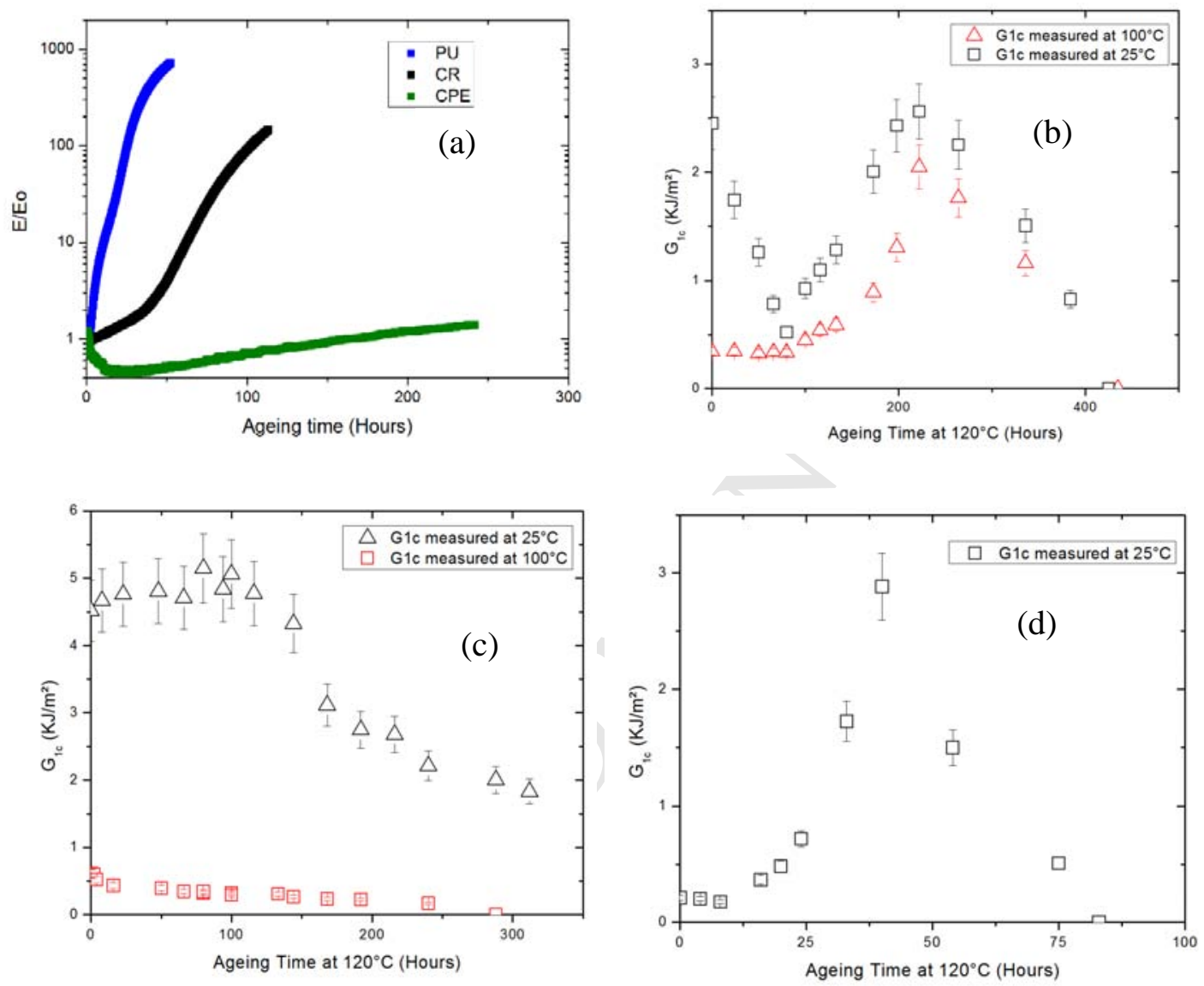

Figure 8 : Effect of oxidation on molecular weight between cross-links for PU, CR and $\mathrm{CPE}$ (a) aged at $120^{\circ} \mathrm{C}$ Modification of $\mathrm{G}_{1 \mathrm{C}}$ measured at 25 and $100^{\circ} \mathrm{C}$ during CR (b), CPE (c), PU (d) oxidation at $120^{\circ} \mathrm{C}$. 


\section{Discussion}

It is clear that CR and PU undergo predominant crosslinking, as evidenced by modulus changes (Figure 8a). In these rubbers, oxidation induced changes can be tentatively used to appreciate the effect of crosslinking on fracture properties. In the case of CPE, the initial modulus decrease indicates a decrease of crosslink density presumably linked to predominant chain scission. A description of the oxidative crosslinking process would involve a relatively complex set of reactions. Crosslinking results predominantly from additions of $\mathrm{P}^{\circ}$ and $\mathrm{POO}^{\circ}$ radicals to double bonds but these additions can be either intermolecular or intramolecular and only the former participate in crosslinking [30]. Some of the double bonds can also be consumed in rearrangement reactions, as for instance epoxide formation in polybutadiene [32]. Crosslinking is thus in competition with many other processes, which explains its relatively low yield (Figure 2).
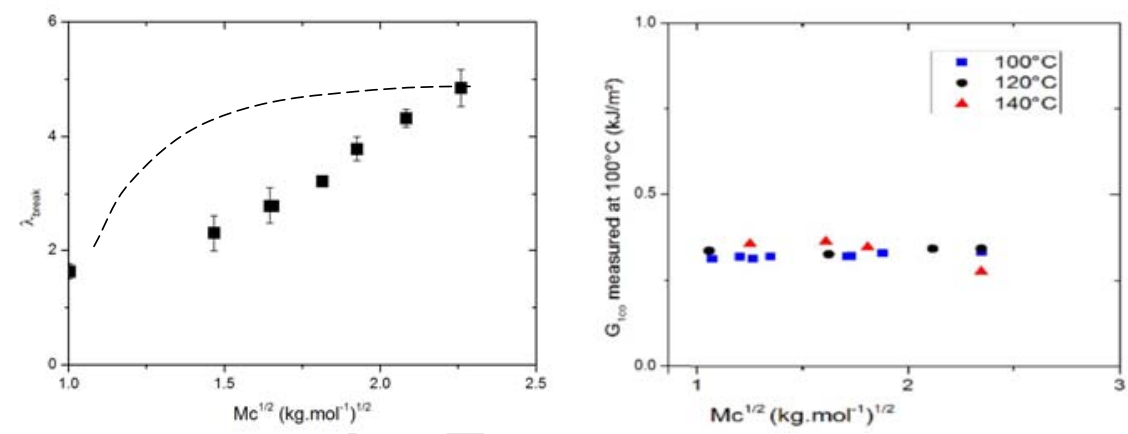

Figure 9 : Elongation at break during oxidation at $100^{\circ} \mathrm{C}$ (a) dashed curves represent evolution with bimodal of chain length (see text) and $G_{1 c o}(b)$ as function of square root of $\mathrm{Mc}$ in $\mathrm{CR}$

Let us first consider the initial decay of fracture properties (both $\lambda_{\mathrm{r}}$ and $\mathrm{G}_{\mathrm{IC}}\left(25^{\circ} \mathrm{C}\right)$ ) for CR. The comparison with PU shows that it involves SIC and the comparison with CPE shows that it is due to crosslinking. In other words, crosslinking, even at low conversion, would inhibit SIC. This is not surprising, we know that for a linear polymer undergoing crosslinking, gelation occurs for a small number $x_{g}$ of crosslinking events [33] [34] :

$x_{g}=1 / M_{w 0}$ 
where $M_{w 0}$ is the initial weight average molar mass of the polymer. A small number of crosslinking events is thus required to increase the viscosity considerably and then significantly reduce the crystallization rate, explaining thus the observed behaviour of CR.

It seemed to us interesting to check a basic result of the simple network theory for period II for which, for affine deformations, in the absence of viscoelasticity, fracture would occur when the chains reach their maximum extension, i.e.:

$\lambda_{r}=K \cdot M_{c}^{1 / 2}$

Since $M_{c}$ can be determined from modulus, we have plotted $\lambda_{r}$ against $M_{c}{ }^{1 / 2}$ in Figure 9a. There are several ways of interpreting this figure. According to the simplest one, the above relationship would be obeyed: $\lambda_{r} \sim(2 \pm 0.4) M_{c}^{1 / 2}$. However, the plot displays a positive curvature which could be linked to a specificity of the crosslinking process and can be explained as follows: random crosslinking creates a new population of chains shorter than initial ones. It is interesting to compare this trend with the one of model networks having a bimodal distribution of chain lengths [1, 2] (Figure 9). In this latter case, it can be seen that the long chains control the ultimate elongation, even at relatively high concentrations of short chains so that $\lambda_{r}$ appears almost independent of $M_{c}$ over a large interval of $\mathrm{M}_{\mathrm{c}}$ values. One can consider that crosslinking creates a new population of short chains (of average length half of that of the initial ones), but the behaviour differs from the preceding one since $\lambda_{\mathrm{r}}$ decreases at low conversions of the crosslinking process (Figure 9). A possible explanation is that if crosslinking is a random process, it must preferentially affect the longer chains. Thus, if these chains controlled the ultimate elongation, the latter is expected to decrease as soon as crosslinking begins.

To appreciate the effect of crosslinking on fracture properties, it is convenient to determine these latter at high temperature, for instance $100^{\circ} \mathrm{C}$, in order to eliminate SIC effects.

The relatively fast toughness increase for $\mathrm{CR}$ at $100^{\circ} \mathrm{C}$ and PU at $25^{\circ} \mathrm{C}$ (absent for CPE) indicates that crosslinking plays a favourable role in fracture, in contradiction with many 
published works according to which rubber toughness is mainly linked to chain extensibility so that:

$G_{I C}=K^{\prime} M_{c}^{1 / 2}$

Here, $G_{I C}$ increases rapidly when $M_{c}$ decreases as a result of oxidative crosslinking, for CR (Figure 9-b) and PU.

It can be noted that, in the case of Llorente's model for bimodal networks [2], the strain energy density at rupture in tension $W_{r}$ is also a decreasing function of $M_{c}$. Assuming that $W_{r}$ and $G_{I C}$ are closely related, we reach the following conclusion: Oxidative crosslinking, due to its bimodal character, does not affect (at low conversions) ultimate elongations but induces an increase of stresses as expected from the theory of rubber elasticity. The existence of a compromise between stiffness and strength in certain rubbers has been recently reported by Roland [35]. As a result, the fracture energy increases with the crosslink density where it would decrease in the case of networks with unimodal distributions of chain lengths.

It remains to explain the last period, common to all materials undergoing crosslinking and all testing temperatures, where the samples undergo a steep, irreversible, and fast embrittlement. In CPE, embrittlement is also observed but it is more progressive. In CR and PU, crosslinking is no doubt the primary cause of the final toughness decay. An explanation can be envisaged. It is once again offered by the Llorente's results on bimodal networks [1] [2]. One sees in these results that when the fraction of short chains increases, the strain energy density at rupture first increases, as previously quoted, but beyond a certain concentration, the ultimate elongation becomes controlled by the short chains and the fracture energy begins to decrease. The maximum of $G_{I C}$ could then correspond to the point where short chains created by the oxidative crosslinking process, begin to take the control of ultimate elongation. The various changes in fracture behaviour are summarized in Table 2 below. 
23

\begin{tabular}{|c|c|c|c|c|c|}
\hline Rubber & $\begin{array}{l}\text { Testing } \\
\text { Temperature } \\
\left({ }^{\circ} \mathrm{C}\right)\end{array}$ & $\begin{array}{l}\text { Step I } \\
\text { Sense of } \\
\text { variation } \\
\text { of } \mathrm{G}_{\mathrm{IC}}\end{array}$ & $\begin{array}{l}\text { Step I } \\
\text { Mechanism }\end{array}$ & $\begin{array}{l}\text { Step II } \\
\text { Sense of } \\
\text { Variatio } \\
\mathrm{n} \\
\text { of } \mathrm{G}_{\mathrm{IC}}\end{array}$ & $\begin{array}{l}\text { Step II } \\
\text { Mechanism }\end{array}$ \\
\hline $\mathrm{CR}$ & 25 & - & $\begin{array}{l}\text { SIC inhibition by } \\
\text { Oxidative } \\
\text { crosslinking }\end{array}$ & + & $\begin{array}{l}\text { Oxidative } \\
\text { crosslinking }\end{array}$ \\
\hline CR & 100 & 0 & No SIC & & $\begin{array}{l}\text { Oxidative } \\
\text { crosslinking }\end{array}$ \\
\hline $\mathrm{PU}$ & 25 & 0 & No SIC & + & $\begin{array}{l}\text { Oxidative } \\
\text { crosslinking }\end{array}$ \\
\hline $\mathrm{CPE}$ & 25 & 0 & No crosslinking & - & No crosslinking \\
\hline CPE & 100 & 0 & No crosslinking & - & No crosslinking \\
\hline
\end{tabular}

Table 2. Summary of the observed changes in fracture properties and their explanation. 


\section{Conclusions}

We have investigated the fracture properties of three rubbers chosen in order to distinguish between the effects of strain induced crystallization and crosslinking on fracture behavior, this latter being examined both by tensile testing and crack propagation studies, at $25^{\circ} \mathrm{C}$ and $100^{\circ} \mathrm{C}$.

The evolution of fracture properties reveals the existence of three consecutive steps of which the last is always a steep embrittlement. The most important phenomenon is SIC because it ensures, initially, a high toughness, with $\mathrm{G}_{\mathrm{IC}}$ values of the order of several $\mathrm{kJ} / \mathrm{m}^{2}$ against a few hundred $\mathrm{J} / \mathrm{m}^{2}$ in the absence of SIC. However, SIC is inhibited by oxidative crosslinking so that its reinforcing effect disappears rapidly in the early period of exposure. $G_{I C}$ decreases by a factor of about 10 so that, at the end of this step, most users would consider that the material has reached the end of its life. Therefore, the first practical conclusion of this study is that the best rubbers, from this point of view, are those which, like CPE, undergo SIC but do not crosslink during their oxidative ageing.

There is however a second step during which, in unsaturated rubbers such as CR and PU, the toughness increases as a result of crosslinking while, according to the basic network theory, it would be expected to decrease. It has been proposed here that this peculiar behavior is linked to the bimodal character of networks resulting from oxidative crosslinking.

This bimodal character is also presumably the cause of the fast final catastrophic embrittlement. 


\section{REFERENCES -}

1. Mark JE and Tang MY. Journal of Polymer Science: Polymer Physics Edition 1984;22(11):1849-1855.

2. Llorente MA, Andrady AL, and Mark JE. Journal of Polymer Science: Polymer Physics Edition 1981;19(4):621-630.

3. Cristiano A, Marcellan A, Keestra BJ, Steeman P, and Creton C. Journal of Polymer Science Part B-Polymer Physics 2011;49(5):355-367.

4. Lake GJ and Lindley PB. Journal of Applied Polymer Science 1965;9(4):12331251.

5. $\quad$ Lake GJ. Rubber Chemistry and Technology 2003;76(3):567-591.

6. Tsunoda K, Busfield JJC, Davies CKL, and Thomas AG. Journal of Materials Science 2000;35(20):5187-5198.

7. Bhowmick AK, Gent AN, and Pulford CTR. Rubber Chemistry and Technology 1983;56(1):226-232.

8. Yanyo LC and Kelley FN. Rubber Chemistry and Technology 1988;61(1):100118.

9. Yanyo LC and Kelley FN. Rubber Chemistry and Technology 1987;60(1):78-88.

10. Persson BNJ, Albohr O, Heinrich G, and Ueba H. Journal of Physics-Condensed Matter 2005;17(44):R1071-R1142.

11. Yanyo LC. International Journal of Fracture 1989;39(1-3):103-110.

12. Trabelsi S, Albouy PA, and Rault J. Macromolecules 2003;36(20):7624-7639.

13. Amnuaypornsri S, Toki S, Hsiao BS, and Sakdapipanich J. Polymer 2012;53(15):3325-3330.

14. Chenal J-M, Chazeau L, Guy L, Bomal Y, and Gauthier C. Polymer 2007;48(4):1042-1046.

15. Tosaka M, Murakami S, Poompradub S, Kohjiya S, Ikeda Y, Toki S, Sics I, and Hsiao BS. Macromolecules 2004;37(9):3299-3309.

16. Azura AR, Goritz D, Muhr A, and Thomas AG. Effect of ageing on the ability of natural rubber to strain crystallise. In: J. Busfield and Muhr A, editors.

Constitutive Models for Rubber III. London, 2003.

17. Huneau B. Rubber Chemistry and Technology 2011;84(3):425-452.

18. Mott PH and Roland CM. Rubber Chemistry and Technology 2001;74(1):79-88.

19. Anh TH and Vu-Khanh T. Journal of Materials Science 2005;40(19):5243-5248.

20. Ha-Anh T and Vu-Khanh T. Polymer Testing 2005;24(6):775-780.

21. Kole S, Roy S, and Bhowmick AK. Polymer 1995;36(17):3273-3277.

22. Planes E, Chazeau L, Vigier G, and Fournier J. Polymer 2009;50(16):4028-4038.

23. Gueguen V. Vieillissement d'elastomeres utilises comme isolants electriques en ambiance nucleaire. [S.1.]: Arts et Métiers ParisTech, 1992.

24. Merckel Y, Diani J, Brieu M, and Caillard J. Journal of Applied Polymer Science 2013;129(4):2086-2091.

25. Celina M, Wise J, Ottesen DK, Gillen KT, and Clough RL. Polymer Degradation and Stability 2000;68(2):171-184.

26. Mayo FR. Industrial \& Engineering Chemistry 1960;52(7):614-618. 
27. Tobolsky AV, Metz DJ, and Mesrobian RB. Journal of the American Chemical Society 1950;72(5):1942-1952.

28. Colin X, Audouin L, and Verdu J. Polymer Degradation and Stability 2007;92(5):886-897.

29. Treloar LRG. The physics of rubber elasticity: Oxford University Press, USA, 1975.

30. Coquillat M, Verdu J, Colin X, Audouin L, and Nevière R. Polymer Degradation and Stability 2007;92(7):1326-1333.

31. Le Gac PY, Broudin M, Davies P, and Fayolle B. Oxidation effect on fracture properties of rubbers. In: Alonso G-N, editor. Constitutive Models for Rubber VIII. San Sebastien: CRC Press, 2013. pp. 25-29.

32. Guyader M, Audouin L, Colin X, Verdu J, and Chevalier S. Polymer Degradation and Stability 2006;91(11):2813-2815.

33. Saito O. Journal of the Physical Society of Japan 1958;13(12):1451-1464.

34. Charlesby A and Pinner SH. Proceedings of the Royal Society of London. Series A. Mathematical and Physical Sciences 1959;249(1258):367-386.

35. Roland CM. Rubber Chemistry and Technology 2013;86(3):351-366. 
27

Appendix 1

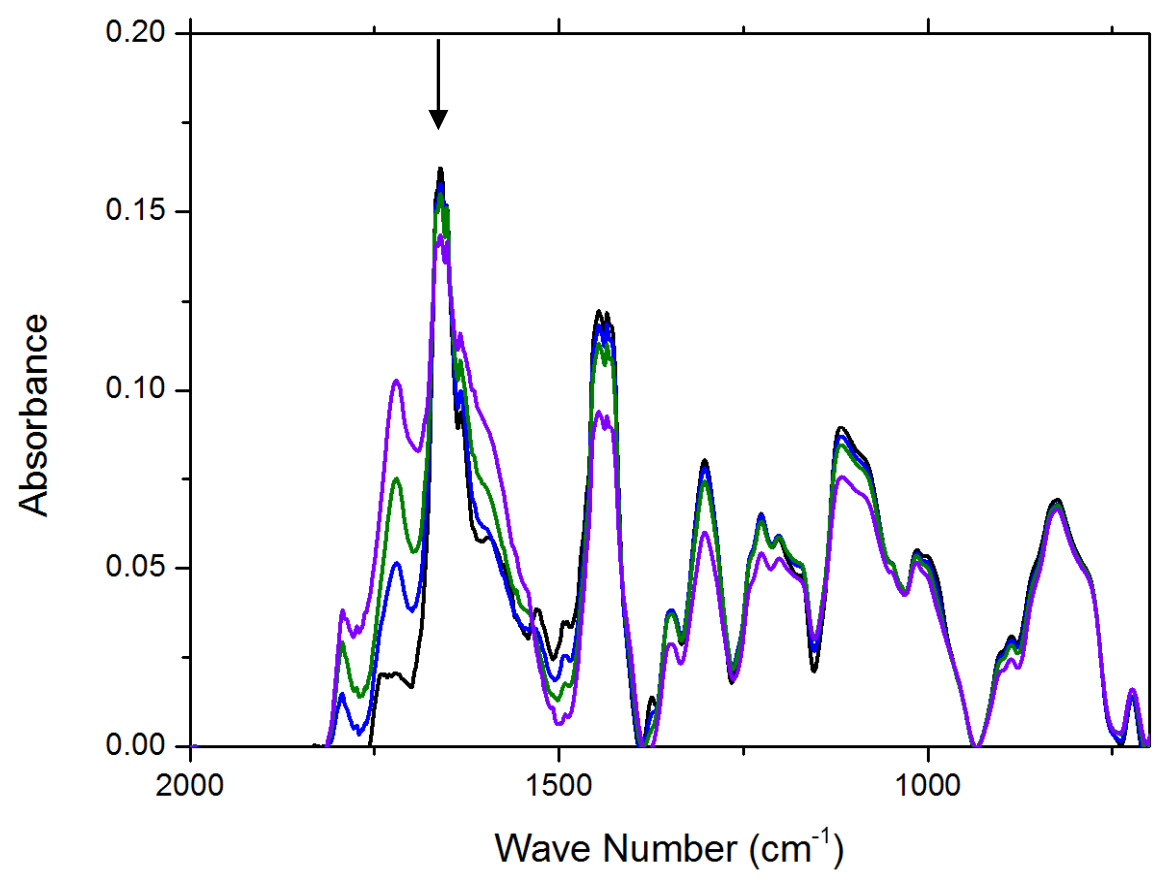

Evolution of infrared spectra with CR oxidation. Arrow shows carbon double bonds band. 